\title{
MORPHOLOGY AND GENETICS OF THE CISCOES (ACTINOPTERYGII: SALMONIFORMES: SALMONIDAE: COREGONINAE: COREGONUS) FROM THE SOLOVETSKY ARCHIPELAGO (WHITE SEA) AS A KEY TO DETERMINATION OF THE TAXONOMIC POSITION OF CISCOES IN NORTHEASTERN EUROPE
}

\author{
Elena A. BOROVIKOVA ${ }^{1 *}$, Yaroslava I. ALEKSEEVA ${ }^{2}$, Maria J. SCHREIDER ${ }^{3}$, \\ Valentina S. ARTAMONOVA ${ }^{4}$, and Alexander A. MAKHROV ${ }^{4}$ \\ ${ }^{1}$ I.D. Papanin Institute for Biology of Inland Waters, Russian Academy of Sciences, Borok, Russia \\ ${ }^{2}$ Shirshov Institute of Oceanology, Russian Academy of Sciences, Moscow, Russia \\ ${ }^{3}$ School of Environmental and Life Sciences, University of Newcastle, NSW 2258, Australia \\ ${ }^{4}$ A.N. Severtsov Institute of Ecology and Evolution, Russian Academy of Sciences, Moscow, Russia
}

Borovikova E.A., Alekseeva Y.I., Schreider M.J., Artamonova V.S., Makhrov A.A. 2013. Morphology and genetics of the ciscoes (Actinopterygii: Salmoniformes: Salmonidae: Coregoninae: Coregous) from the Solovetsky Archipelago (White Sea) as a key to determination of the taxonomic position of ciscoes in northeastern Europe. Acta Ichthyol. Piscat. 43 (3): 183-194.

Background. The characteristic feature of the genus Coregonus is the multitude of nominal species of obscure identity. The northeastern Europe is inhabited by, inter alia - the vendace, Coregonus albula (Linnaeus, 1758) considered the European cisco- and the least cisco, C. sardinella Valenciennes, 1848 - often referred to as the Siberian species. There is a large area in where the ranges of both species overlap. Using morphological- as well as genetic tools we attempted to test the working hypothesis that the Coregonus fish (ciscoes) inhabiting the above-mentioned transitional zone represent a single species.

Materials and methods. Within 1995-2009 we collected 344 ciscoes from five lakes in Bolshoy Solovetsky Island and determined diagnostic morphological traits for the two species. For some samples, the polymorphism of the creatine kinase isoloci $\left(C K-A 1,2^{*}\right)$ and the fragment of mitochondrial DNA (mtDNA) encoding the subunit 1 of NADH-dehydrogenize complex (ND-1 fragment) was also studied.

Results. According to one of the main taxonomical characteristics - the number of vertebrae - the cisco of Solovetsky Island occupies an intermediate position between C. albula and C. sardinella. The molecular markers, however, did not reveal any differences between the ciscoes of Bolshoy Solovetsky Island and the vendace found elsewhere. All specimens had the type allele of creatine kinase $\left(C K-A^{*} 100\right)$ which was considered to be typical for $C$. albula at other locations as well as the haplotype $\mathrm{E}$ of mtDNA widespread in vendace populations. Conclusion. The cisco from Solovetsky Island is more similar to typical vendace. Differences in some morphological traits between Solovetsky Island populations and the vendace from elsewhere are likely to reflect adaptation to environmental conditions. Thus it appears that morphological criteria do not allow reliable differentiation between two forms of ciscoes as well as between least cisco and vendace because they are influenced by environmental conditions. We believe that the presence of populations with intermediate features is a strong argument for combining $C$. albula and $C$. sardinella into a single species (C. albula).

Keywords: ciscoes, morphological characteristics, creatine kinase isoloci, $N D-1$ fragment mtDNA, taxonomy, phylogeography

\section{INTRODUCTION}

Examining the morphological and genetic characteristics of cisco populations in northeastern Europe is likely to lead to important insights into both the evolution and biogeography of this group. As seen in other fish species (e.g., Kottelat and Freyhof 2007), many members of the Coregoninae quickly diverge into distinct forms (Hudson et al. 2007).
These are, sometimes prematurely, given a status of species (Svärdson 1988, Kottelat and Freyhof 2007). These morphologically 'distinct' forms, however, are also known to revert to a more common form when reared in controlled environments, suggesting that the presence of morphological characteristics does not actually mean that each populations should deserve the 'species' status (Vonlanthen et al. 2012).

\footnotetext{
* Correspondence: Dr Elena A. Borovikova, ФГБУН Институт биологии внутренних вод им. И.Д. Папанина Российской Академии наук, 152742 Воrok, Nekouzsky district, Yaroslavl region, Russia, phone: +7 48547-24-5-26, fax: +7 48547-24-0-42, e-mail: elenalex1@yandex.ru.
} 
Northern Europe is a region where a significant overlap exists between European and Siberian fauna. Many species, particularly those which have originated from Siberia, have been relatively poorly studied (Segerstråle 1976, Kuderskij 1987, Bănărescu 1991, Pervozvansky 1999, Makhrov and Bolotov 2006). Insofar as coregonids are concerned, the wider geographical area where both European and Siberian forms are present has been subjected to scientific scrutiny for nearly a century (see references in Borovikova and Makhrov 2009). The existence of such transitional zone means that determining the distributional boundaries of European and Siberian ciscoes, as well as describing their taxonomic status and phylogenetic relations is difficult.

One of the first references to the presence of a Siberian form, least cisco, Coregonus sardinella Valenciennes, 1848, in Northern Europe can be found in Berg (1916). He described a sub-species of the White Sea cisco, Coregonus sardinella marisalbi based on specimens caught near the Solovetsky Archipelago. Pokrovskij (1967) later demonstrated that the distribution of this subspecies was more widespread. He suggested that the same sub-species could be found in water bodies in the catchments bordered by the Arctic Ocean (basins of rivers Pechora, Indiga, and Mezen; lakes of Bolshezemelsky tundra and Kolguyev Island), and the Baltic Sea (e.g., Vodlozero Lake in the Onega Lake sub-catchment). Another sub-species of least cisco-C. sardinella vessicus-was described from Lake Beloye which is located in the upper reaches of the Volga River near the watershed between the Baltic and White seas (Drâgin 1933).

The presence of fish with intermediate morphological characters in the Solovetsky lakes and from Lake Beloye, suggested that specimens captured from these sites could be classified as being either least cisco or vendace (Drâgin 1933, Kuziŝin et al. 1999, Dvorânkin 2005). Additional studies have, by contrast, suggested that the ciscoes from the lakes of Bolshoy Solovetsky Island are 'typical' Coregonus albula (Linnaeus, 1758) (see Zahvatkin 1927, Muhomediârov 1963).

Interestingly, Kuziŝin et al. (1999) observed changes in the external morphology of vendace from Lake Krasnoye over a period of 25 years. So whilst this population had been earlier identified by Muhomediârov (1963) as being 'typical' vendace, the specimens obtained from Lake Krasnoye in 1989 were morphologically more similar to least cisco (Kuzisiin et al. 1999).

Confusion relating to the taxonomic status of ciscoes from Solovetsky Archipelago has been further complicated by the use of different diagnostic characteristics by the various authors. To correct this, Rešetnikov (2003) attempted to streamline the identification of vendace using basic morphological characteristics. Using these 'rules', fish can be identified as a vendace if the antedorsal length (expressed as a percentage of fork length) exceeds $42 \%$ and vertebral counts are 54 to 59 (more commonly 55-56). Least cisco has 57-64 vertebrae, and this figure is often more than 60 . Using these basic morphological criteria it has been suggested that the distribution of least cisco in Europe is limited by the outermost northeastern part (Chesha Bay and Pechora basin), and does not include the Solovetsky Archipelago (Rešetnikov 2003).

Determining the taxonomic status and likely origin of ciscoes populations from the Solovetsky Archipelago is crucial if we are to fully understand of the phylogeny and phylogeography of ciscoes of northeastern Europe.

This study attempts to improve our understanding of the nature of the transitional zone between European and Siberian ciscoes in northeastern Europe. To do that we tested the working hypothesis that the Coregonus fish (ciscoes) inhabiting the above-mentioned transitional zone represent a single species (Coregonus albula). We examined populations of ciscoes from Solovetsky Archipelago, using a combined analysis of multiple morphological characteristics and molecular markers from nuclear and mitochondrial genomes.

\section{MATERIALS AND METHODS}

Collection and preservation of material. A total of 344 ciscoes were caught with set nets (mesh size 12-20 mm) from five lakes on Bolshoy Solovetsky Island from 1995 up to 2009 (Fig. 1, Table 1). Collection of the fish was performed in accordance with permits of the administration of the culture preserve "Solovetsky". It is important to mention that four lakes (Bolshoye Krasnoye, Nizhniy Pert, Sredniy Pert, and Bolshoye Gremyachye) are connected by canals while Lake Goreloye is not included in this canal systems.

Morphological analysis was carried out on all fish captured during this research project. Studies relating to genetic polymorphism, using nuclear- (creatine kinase isoloci) and mitochondrial ( $N D-1$ fragment of mtDNA) markers, were only performed using samples obtained during the period of 2008-2009. To study polymorphism using creatine kinase samples of the white muscles, which were quickly frozen in liquid nitrogen $\left(-70^{\circ} \mathrm{C}\right)$, were used. For mtDNA analysis the muscle tissue samples were fixed in $96 \%$ ethanol.

Morphological analysis. Morphological characteristics were described using the methodology previously used for coregonids from northeastern Europe (Pravdin 1966) (Fig. 2). Since Berg (1916) does not provide data on the number of vertebrae in the type specimen of Coregonus sardinella marisalbi, we counted their number on the X-ray image of the type specimen from Zoological Institute (Russian Academy of Sciences).

Analysis of creatine kinase isoloci $\boldsymbol{C K}-\boldsymbol{A 1}, 2 *$. Each sample of white muscle tissue (piece measuring $5 \times 5 \times 5 \mathrm{~mm}^{3}$ ) was placed in an amount equal to its volume of TRIS extraction buffer (containing $0.015 \mathrm{~mol}$ Tris- $\mathrm{HCl}, \mathrm{pH} 7.5$, and $20 \%$ sucrose). It was then homogenized at 0 to $4{ }^{\circ} \mathrm{C}$. Vertical polyacrylamide gel electrophoresis was performed in $7.5 \%$ polyacrylamide using Tris-Borate-EDTA (TBE) buffer. Gel, stock solutions and Tris-Borate-EDTA (TBE) buffer were prepared according Peacock et al. (1965). Voltage was applied for $20 \mathrm{~min}$ before addition of 
the samples. Twelve $\mathrm{mL}$ of extract from white muscle were applied to each slot. For cooling of cells water at 0 to $4^{\circ} \mathrm{C}$ was used throughout the run. If the length of gel was $8-10 \mathrm{~cm}$ a potential difference $230-260 \mathrm{~V}$ was applied which resulted in a current of approximately $60-80 \mathrm{~mA}$ at the end of the run $(2 \mathrm{~h})$. Vertical electrophoresis was performed in cells designed by Truveller and Nefëdov (1974).
Creatine kinase loci $C K-1,2^{*}$ analysis allows Coregonus albula and C. sardinella from Siberia to be differentiated via the presence or absence of some alleles (Perelygin 1992, Sendek 2002). Staining for general protein, including products of the creatine kinase loci, was carried out according to the method described by Gaál et al. (1980). It should be noted for improving of the results we slightly modified this method. So we changed the ratio
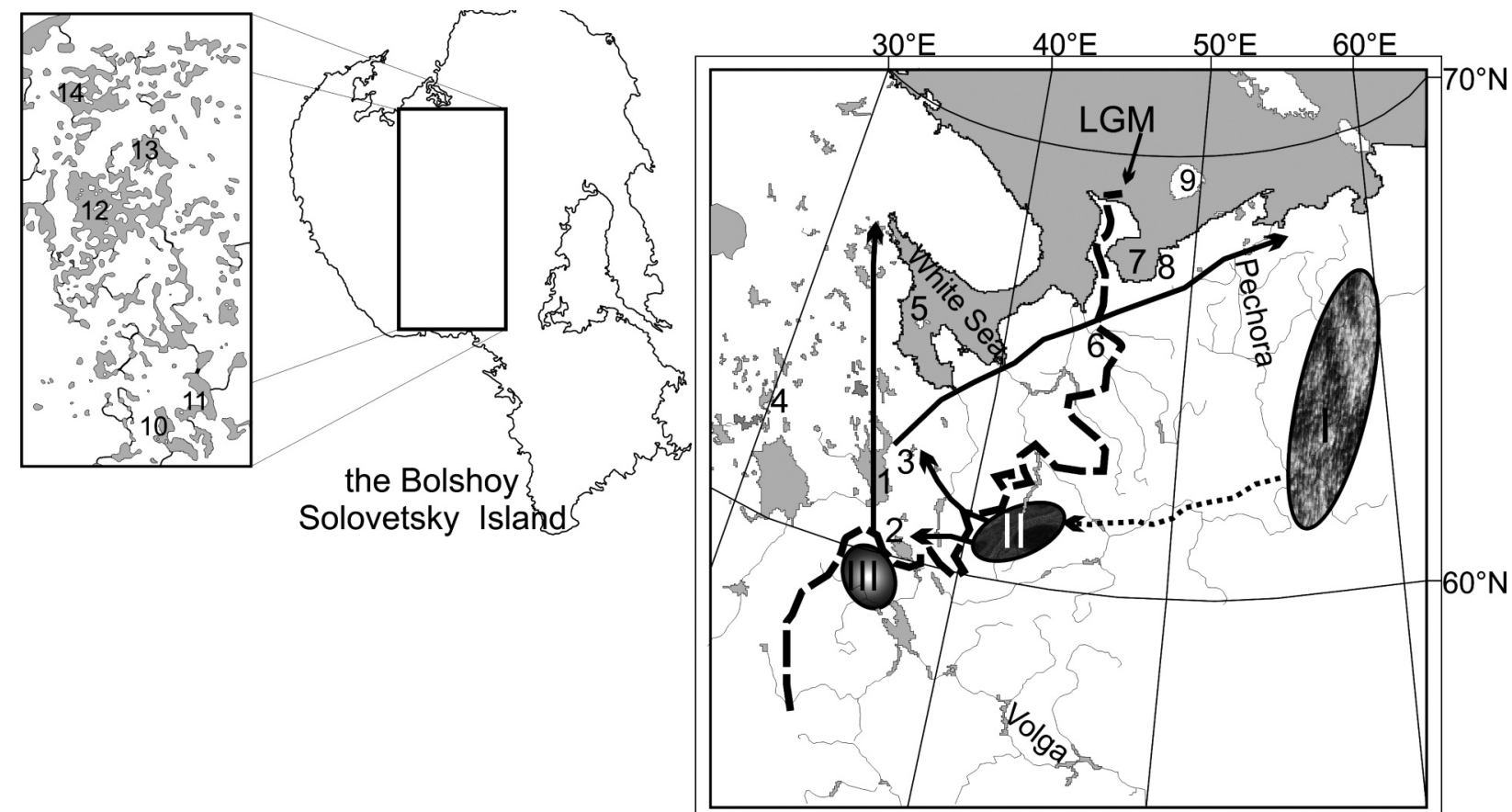

Fig. 1. The map of Northwestern Russia with the main water bodies discussed in the study; LGM = Last Glacial Maximum (according to Svendsen et al. 2004); 1 = Lake Onega; 2 = Lake Beloye; $3=$ Lake Vodlozero; $4=$ Lake Puruvesi; 5 = Solovetsky Archipelago; $6=$ Mezen River; 7 = Chesha Bay; $8=$ Indiga River; $9=$ Kolguyev Island; 10 = Lake Nizhniy Pert; 11 = Lake Sredniy Pert; 12 = Lake Bolshoye Krasnoye; 13 = Lake Bolshoye Gremyachye; 14 = Lake Goreloye; Roman numerals indicate refugia; Arrows indicate the main hypothesized directions of the ciscoes' spread before and after last glacial period

Table 1

Summary of the populations sampled in the presently reported study

\begin{tabular}{|c|c|c|c|c|c|c|c|}
\hline \multirow{2}{*}{ Lake } & \multicolumn{2}{|c|}{ Coordinates } & \multirow{2}{*}{$\begin{array}{c}\text { Year } \\
\text { sampled }\end{array}$} & \multicolumn{3}{|c|}{ Sample size } & \multirow{2}{*}{ Total } \\
\hline & Latitude & Longitude & & MA & IA & MTA & \\
\hline \multirow[t]{2}{*}{ Sredniy Pert } & $65^{\circ} 03^{\prime} \mathrm{N}$ & $35^{\circ} 43^{\prime} \mathrm{E}$ & 1995 & 63 & - & - & 63 \\
\hline & & & 1995 & 11 & - & - & \\
\hline \multirow[t]{3}{*}{ Nizhniy Pert $=$ Khutorskoe } & $65^{\circ} 02^{\prime} \mathrm{N}$ & $35^{\circ} 41^{\prime} \mathrm{E}$ & 1996 & 90 & - & - & 156 \\
\hline & & & 2008 & 55 & 55 & 55 & \\
\hline & & & 1996 & 5 & - & - & \\
\hline \multirow[t]{2}{*}{ Bolshoye Krasnoye } & $65^{\circ} 05^{\prime} \mathrm{N}$ & $35^{\circ} 42^{\prime} \mathrm{E}$ & 1997 & 35 & - & - & 93 \\
\hline & & & 2008 & 53 & 53 & 53 & \\
\hline \multirow{2}{*}{ Bolshoye Gremyachye } & \multirow{2}{*}{$65^{\circ} 07^{\prime} \mathrm{N}$} & \multirow{2}{*}{$35^{\circ} 42^{\prime} \mathrm{E}$} & 1997 & 5 & - & - & \multirow{2}{*}{12} \\
\hline & & & 2008 & 7 & 7 & 7 & \\
\hline Goreloye $=$ Bolshoye Ostrechye $\mathrm{e}^{\#}$ & $65^{\circ} 08^{\prime} \mathrm{N}$ & $35^{\circ} 50^{\prime} \mathrm{E}$ & 2009 & 20 & 20 & 20 & 20 \\
\hline Total & & & & 344 & 135 & 135 & \\
\hline
\end{tabular}

$\mathrm{MA}=$ morphological analysis; $\mathrm{IA}=$ analysis of polymorphism of creatine kinase isoloci $C K-A 1,2 *$; MTA, PCR-RFLP analysis of mtDNA; "denotes lakes which are known by two names. 
of the coomassie, trichloracetic acid, and ethanol and concentration of trichloracetic acid $(0.005 \mathrm{~g}$ coomassie was diluted in $0.100 \mathrm{~L}$ ethanol and the total volume was brought to $1 \mathrm{~L}$ with $15 \%$ trichloracetic acid). The gel made of the mix was left for $12-16 \mathrm{~h}$ for staining to develop. Fifteen specimens of 'typical' vendace from Lake Puruvesi, Finland, were used as controls.

PCR-RFLP analysis of mitochondrial ND-1 fragment. Total cell DNA was isolated from ethanol-preserved specimens by the phenol-chloroform extraction protocol (Green and Sambrook 2012) or the DNA kit Diatom ${ }^{\circledR}$ DNAPrep100 (manufactured by "Izogen", Moscow, www.rugenlab.ru ).

For PCR-RFLP analysis the amplified mtDNA fragment of 2050 bp including the gene that encodes subunit 1 of NADH-dehydrogenase complex (ND-1; hereafter referred to as $N D-1$ fragment) was used. The amplification was performed using the primers developed by Cronin et al. (1993): 5'ACCCCGCCTGTTTACCAAAAACAT3' (LGL381, forward) and 5'GGTTCATTAGTGAGGGAAGG3' (LGL563, reverse).

Synthesis of fragments (polymerase chain reaction, PCR) was conducted in $25 \mu \mathrm{L}$ of $\times 1$ amplification buffer from "Bion-m" (Moscow): $0.010 \mathrm{~mol}$ Tris- $\mathrm{HCl}(\mathrm{pH} 8.8)$; $0.050 \mathrm{~mol} \mathrm{KCl} ; 2.5 \mathrm{mmol} \mathrm{MgCl}_{2}$, and $0.08 \%$ Nonidet P40. The amplification mixture contained 100-300 ng of total cell DNA, 10-15 pmol of each of the two primers, $200 \mathrm{nmol}$ dNTPs, and 0.5-1 units of Taq polymerase ("Bion-m", Moscow or "Fermentas", Lithuania). A small amount of mineral oil was added on the surface during PCR to avoid evaporation.

Amplification program of $N D-1$ fragment included initial DNA denaturation step at $95^{\circ} \mathrm{C}$ for $5 \mathrm{~min} ; 32$ cycles of fragment synthesis at $95^{\circ} \mathrm{C}$ for $1 \mathrm{~min}, 53^{\circ} \mathrm{C}$ for $50 \mathrm{~s}, 72^{\circ} \mathrm{C}$ for $1 \mathrm{~min} 45 \mathrm{~s}$, and final elongation at $72^{\circ} \mathrm{C}$ for $5 \mathrm{~min}$.

The amplified fragments of mtDNA were investigated by means of 14 restriction endonucleases (AseI, Bst NI, BstUI, DdeI, DpnII, HaeIII, HhaI, HincII, Hinfl, HphI, MspI, NciI, RsaI, TagI). Seven $\mu \mathrm{L}$ of reaction mix contained $0.7 \mu \mathrm{L}$ of $\times 10$ buffer as recommended by the manufacturers ("Sibenzyme", Novosibirsk or "Fermentas", Lithuania), 2-4 $\mu \mathrm{L}$ of PCR product and $0.5-1$ units of the enzyme. For DdeI and HaeIII we used $14 \mu \mathrm{L}$ of reaction mix, because the products were analyzed both in agarose and polyacrylamide gels. Endonuclease treatment of samples was carried out for 3-4 h at the temperature recommended by manufacturers.

Fragment length analysis of the cut amplification products were performed in $2 \%$ gel for all endonucleases except BstNI. For the latter, the fragment lengths were analyzed in $1.3 \%$ agarose gel. Electrophoresis was done using Tris-Acetate-EDTA (TAE) or Tris-Borate-EDTA (TBE) buffer systems (Green and Sambrook 2012). To reveal polymorphisms of low-weight molecular fragments, the products of cutting ND-1 fragment by $D d e \mathrm{I}$ and HaeIII were also run in $11 \%$ polyacrylamide gel with TBE buffer. After electrophoresis agarose and polyacrylamide gels were stained with ethidium bromide. Composite haplotypes were created for each sample and labelled following Borovikova (unpublished*) and Borovikova and Makhrov (2009).

Data analysis. Differentiation of the ciscoes populations on number of vertebrae was tested with $\chi^{2}$. For estimate of the significance of mean values' differences Student's $t$-test was performed (Ivanter and Korosov 2003). In case of the morphological traits expressed as the percentage for improve normality we transformed data using arcsine transformation.

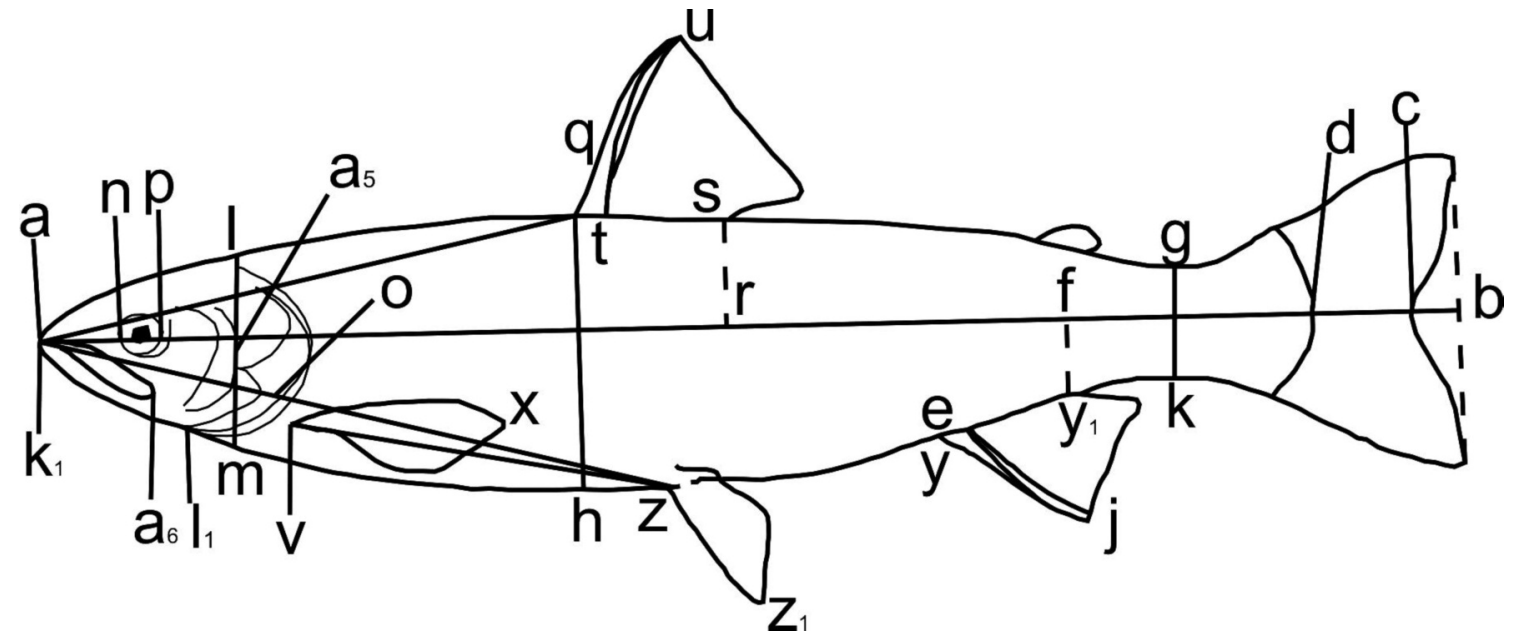

Fig. 2. The measurement diagram used for coregonid fish (Pravdin 1966 ${ }^{1}$, modified after Smitt 1886): a-b, total length; a-c, fork length; a-d, length to the end of scale cover; o-d, trunk length; $\mathrm{g}-\mathrm{h}$, maximum body depth; g-k, minimal body depth; a-q, antedorsal distance; $r-d$, postdorsal distance; $a-z$, anteventral distance; a-y, anteanal distance; $\mathrm{z}-\mathrm{y}$, ventroanal distance; $\mathrm{f}-\mathrm{d}$, caudal peduncle length; q-s, length of dorsal fin; $\mathrm{t}-\mathrm{u}$, maximum height of dorsal fin; $y-y_{1}$, length of anal fin; $e-j$, maximum height of anal fin; $v-x$, length of pectoral fin; $z-z_{1}$, length of ventral fin; $v-z$, pectroventral distance; $a-n$, length of snout; $n-p$, horizontal eye diameter; $a-a_{5}$, length of middle part of the head; $\mathrm{a}-\mathrm{o}$, length of head; $\mathrm{p}-\mathrm{o}$, post-orbital distance; $1-\mathrm{m}$, height of head near the occiput; a-a 6 , upper jaw length; $\mathrm{k}_{1}-\mathrm{l}_{1}$, lower jaw length 


\section{RESULTS}

Morphological characteristics of ciscoes from Bolshoy Solovetsky Island. All specimens were small in size, ranging between 16 and $20 \mathrm{~cm}$ fork length with only a few specimens exceeding $21 \mathrm{~cm}$. Total weight varied between 13 and $167 \mathrm{~g}$ (Table 2).

While average antedorsal length (as a percentage of fork length) was typical for vendace, we also found specimens whose measurements were characteristic of least cisco. Notably, the number of vertebrae in the fish caught in Solovetsky lakes was also greater than might be expected in a 'typical' vendace. Our specimens had an average of 57-58 vertebrae with some reaching 59-60. Note that the type specimen of White Sea cisco described by Berg (1916) had 59 vertebrae.

The ciscoes from Bolshoye Gremyachye Lake were somewhat different, however: it had the smallest number of vertebrae, which made it more similar to the European form compared to other populations (Tables 2, 3). At the same time, the dorsal fin had an anterior position which

Some meristic and plastic traits of ciscoes from Bolshoy Solovetsky Island

Table 2

\begin{tabular}{|c|c|c|c|c|c|c|c|c|c|}
\hline \multirow{2}{*}{\multicolumn{2}{|c|}{ Trait }} & \multicolumn{8}{|c|}{ Population code } \\
\hline & & G & BOD & SP & SPD & NP & $\mathrm{BK}$ & BKM & $\mathrm{BG}$ \\
\hline \multicolumn{2}{|l|}{$n$} & 20 & 52 & $36-64$ & 26 & $15-154$ & $26-93$ & 72 & 7 \\
\hline \multicolumn{2}{|c|}{$\mathrm{FL}[\mathrm{mm}]$} & $\begin{array}{c}167-208 \\
182.3 \pm 0.2\end{array}$ & - & $\begin{array}{c}160-228(64) \\
195.9 \pm 0.2\end{array}$ & - & $\begin{array}{c}128-257(154) \\
175.8 \pm 0.2\end{array}$ & $\begin{array}{c}125-212(93) \\
160.4 \pm 0.1\end{array}$ & $\begin{array}{c}130-260 \\
162.0 \pm 0.1\end{array}$ & $\begin{array}{c}157-183 \\
166.8 \pm 0.5\end{array}$ \\
\hline \multicolumn{2}{|c|}{$W[\mathrm{~g}]$} & $\begin{array}{c}43.4-69.557 .9 \\
\pm 1.6\end{array}$ & - & $\begin{array}{c}39.2-117.1(64) \\
74.0 \pm 2.3\end{array}$ & - & $\begin{array}{c}17.7-167.0(98) \\
50.1 \pm 2.8\end{array}$ & $\begin{array}{c}13.3-84.2(92) \\
31.8 \pm 1.0\end{array}$ & - & $\begin{array}{l}13.9-34.7 \\
24.8 \pm 2.5\end{array}$ \\
\hline \multicolumn{2}{|l|}{ NV } & $\begin{array}{c}56-59 \\
57.5 \pm 0.3\end{array}$ & $\begin{array}{c}55-61 \\
58.1 \pm 0.2\end{array}$ & $\begin{array}{c}56-60(51) \\
58.1 \pm 0.1\end{array}$ & $\begin{array}{c}56-59 \\
57.8 \pm 0.2\end{array}$ & $\begin{array}{c}55-60(112) \\
57.8 \pm 0.1\end{array}$ & $\begin{array}{c}55-60(83) \\
57.7 \pm 0.1\end{array}$ & $54-58$ & $\begin{array}{c}55-58 \\
56.7 \pm 0.4\end{array}$ \\
\hline \multicolumn{2}{|l|}{ NSLL } & - & - & $\begin{array}{l}80-92(36) \\
84.9 \pm 0.5\end{array}$ & $\begin{array}{c}75-90 \\
83.5 \pm 0.9\end{array}$ & $\begin{array}{l}74-95(81) \\
85.8 \pm 0.4\end{array}$ & $\begin{array}{l}80-91(29) \\
85.7 \pm 0.6\end{array}$ & $\begin{array}{c}76-91 \\
81.9 \pm 0.7\end{array}$ & - \\
\hline \multicolumn{2}{|l|}{ NGR } & $\begin{array}{c}40-49(17) \\
44.6 \pm 0.6\end{array}$ & $\begin{array}{c}43-52 \\
47.9 \pm 0.3\end{array}$ & $\begin{array}{c}41-54(49) \\
46.7 \pm 0.4\end{array}$ & $\begin{array}{c}45-53 \\
47.7 \pm 0.4\end{array}$ & $\begin{array}{c}31-51(80) \\
45.0 \pm 0.3\end{array}$ & $\begin{array}{c}44-50(26) \\
45.9 \pm 0.3\end{array}$ & $\begin{array}{c}40-49 \\
45.2 \pm 0.2\end{array}$ & - \\
\hline \multicolumn{2}{|l|}{ NDBR } & $\begin{array}{c}8-10 \\
9.1 \pm 0.1\end{array}$ & - & $\begin{array}{l}8-10(42) \\
9.0 \pm 0.1\end{array}$ & - & $\begin{array}{l}8-11(91) \\
9.0 \pm 0.1\end{array}$ & $\begin{array}{l}8-10(31) \\
8.7 \pm 0.1\end{array}$ & $\begin{array}{c}7-10 \\
8.3 \pm 0.1\end{array}$ & - \\
\hline \multicolumn{2}{|c|}{ NABR } & $\begin{array}{c}11-14 \\
12.4 \pm 0.2\end{array}$ & $\begin{array}{c}9-14 \\
12.4 \pm 0.2\end{array}$ & $\begin{array}{c}11-13(41) \\
12.1 \pm 0.1\end{array}$ & $\begin{array}{c}11-13 \\
12.1 \pm 0.1\end{array}$ & $\begin{array}{c}10-15(98) \\
12.5 \pm 0.1\end{array}$ & $\begin{array}{c}10-13(31) \\
12.1 \pm 0.1\end{array}$ & $\begin{array}{c}10-14 \\
11.4 \pm 0.1\end{array}$ & - \\
\hline \multicolumn{2}{|l|}{ NVBR } & $\begin{array}{c}9-10 \\
9.7 \pm 0.1\end{array}$ & - & $\begin{array}{l}9-10(42) \\
9.8 \pm 0.1\end{array}$ & - & $\begin{array}{l}8-11(15) \\
10.1 \pm 0.2\end{array}$ & - & $9-11$ & - \\
\hline \multicolumn{2}{|l|}{ NPBR } & $\begin{array}{c}13-14 \\
13.7 \pm 0.1\end{array}$ & - & $\begin{array}{l}11-15(41) \\
13.2 \pm 0.1\end{array}$ & - & $\begin{array}{c}12-16(15) \\
14.1 \pm 0.3\end{array}$ & - & $12-15$ & - \\
\hline \multicolumn{2}{|c|}{$\mathrm{VA}$ as $\%$ of $\mathrm{AD}$} & $\begin{array}{l}49.4-59.5 \\
55.5 \pm 0.7\end{array}$ & $\begin{array}{l}46.8-66.7 \\
55.3 \pm 0.5\end{array}$ & $\begin{array}{c}41.5-67.1(61) \\
56.7 \pm 0.6\end{array}$ & $\begin{array}{l}48.7-64.3 \\
55.2 \pm 0.8\end{array}$ & $\begin{array}{c}44.9-62.1(115) \\
53.6 \pm 0.3\end{array}$ & $\begin{array}{c}45.8-71.6(84) \\
55.6 \pm 0.6\end{array}$ & $56.1^{\mathrm{M}}$ & $\begin{array}{c}44.4-59.9(6) \\
52.4 \pm 2.3\end{array}$ \\
\hline \multirow{7}{*}{ 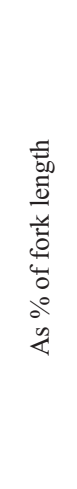 } & $\mathrm{AD}$ & $\begin{array}{l}42.3-46.1 \\
44.3 \pm 0.2\end{array}$ & $\begin{array}{l}42.1-46.3 \\
43.8 \pm 0.1\end{array}$ & $\begin{array}{l}37.9-46.2(50) \\
\quad 42.4 \pm 0.2\end{array}$ & $\begin{array}{l}41.2-45.6 \\
43.4 \pm 0.2\end{array}$ & $\begin{array}{c}36.9-46.3(123) \\
42.9 \pm 0.1\end{array}$ & $\begin{array}{c}34.8-46.7(77) \\
42.7 \pm 0.2\end{array}$ & $43.8 \pm 0.4$ & $\begin{array}{c}40.5-42.4(5) \\
41.4 \pm 0.4\end{array}$ \\
\hline & VA & $\begin{array}{l}21.7-27.0 \\
24.5 \pm 0.3\end{array}$ & $\begin{array}{l}20.7-28.4 \\
24.2 \pm 0.2\end{array}$ & $\begin{array}{c}18.0-29.9(49) \\
24.0 \pm 0.2\end{array}$ & $\begin{array}{l}21.4-27.0 \\
23.9 \pm 0.3\end{array}$ & $\begin{array}{c}19.6-25.4(114) \\
23.1 \pm 0.1\end{array}$ & $\begin{array}{c}19.8-27.7(77) \\
23.7 \pm 0.2\end{array}$ & $24.6 \pm 0.3$ & $\begin{array}{c}20.4-24.2(5) \\
22.4 \pm 0.7\end{array}$ \\
\hline & AV & $\begin{array}{l}44.6-49.7 \\
46.5 \pm 0.3\end{array}$ & $\begin{array}{l}43.2-49.1 \\
46.1 \pm 0.2\end{array}$ & $\begin{array}{c}41.7-49.8(45) \\
46.0 \pm 0.3\end{array}$ & $\begin{array}{l}43.9-49.5 \\
46.7 \pm 0.3\end{array}$ & $\begin{array}{c}40.9-49.5(99) \\
46.1 \pm 0.2\end{array}$ & $\begin{array}{c}44.1-49.0(26) \\
46.9 \pm 0.2\end{array}$ & - & - \\
\hline & PV & $\begin{array}{l}26.9-30.4 \\
28.8 \pm 0.2\end{array}$ & - & $\begin{array}{l}26.2-31.1(42) \\
28.0 \pm 0.2\end{array}$ & - & $\begin{array}{c}14.2-31.1(85) \\
27.6 \pm 0.2\end{array}$ & $\begin{array}{c}24.1-28.7(26) \\
27.0 \pm 0.2\end{array}$ & $28.8 \pm 0.2$ & - \\
\hline & $\operatorname{Hmax}$ & $\begin{array}{l}17.8-21.9 \\
20.1 \pm 0.3\end{array}$ & $\begin{array}{l}17.3-24.1 \\
20.3 \pm 0.2\end{array}$ & $\begin{array}{c}17.0-21.4(50) \\
19.3 \pm 0.2\end{array}$ & $\begin{array}{l}17.7-23.8 \\
20.1 \pm 0.2\end{array}$ & $\begin{array}{c}16.1-21.1(100) \\
18.3 \pm 0.1\end{array}$ & $\begin{array}{c}13.8-18.6(26) \\
16.4 \pm 0.3\end{array}$ & - & - \\
\hline & $\mathrm{LCP}$ & $\begin{array}{l}12.6-17.6 \\
14.5 \pm 0.3\end{array}$ & - & $\begin{array}{c}12.5-16.4(43) \\
14.7 \pm 0.1\end{array}$ & - & $\begin{array}{c}11.7-19.2(99) \\
14.7 \pm 0.1\end{array}$ & $\begin{array}{c}13.2-16.6(26) \\
15.3 \pm 0.2\end{array}$ & $13.9 \pm 0.2$ & - \\
\hline & $\mathrm{HL}$ & $\begin{array}{l}17.4-20.5 \\
18.9 \pm 0.2\end{array}$ & $\begin{array}{l}19.5-22.4 \\
20.8 \pm 0.2\end{array}$ & $\begin{array}{c}16.2-20.8(43) \\
18.8 \pm 0.1\end{array}$ & $\begin{array}{l}19.3-22.5 \\
20.6 \pm 0.1\end{array}$ & $\begin{array}{c}15.5-25.0(118) \\
18.9 \pm 0.1\end{array}$ & $\begin{array}{c}19.5-24.1(26) \\
21.1 \pm 0.2\end{array}$ & $21.3 \pm 0.1$ & - \\
\hline \multirow{2}{*}{$\begin{array}{l}\boxminus \\
0^{\circ}\end{array}$} & NED & $\begin{array}{l}23.5-29.4 \\
26.1 \pm 0.5\end{array}$ & - & $\begin{array}{l}23.7-30.3(43) \\
27.3 \pm 0.3\end{array}$ & - & $\begin{array}{c}18.0-32.1(98) \\
26.9 \pm 0.2\end{array}$ & $\begin{array}{c}25.0-31.3(31) \\
28.6 \pm 0.3\end{array}$ & $27.9 \pm 0.4$ & - \\
\hline & LUJ & $\begin{array}{l}26.8-39.4 \\
34.4 \pm 0.7\end{array}$ & - & $\begin{array}{c}32.4-43.2(43) \\
37.3 \pm 0.3\end{array}$ & - & $\begin{array}{c}25.6-43.5(99) \\
37.0 \pm 0.2\end{array}$ & $\begin{array}{c}30.3-41.4(31) \\
35.5 \pm 0.4\end{array}$ & - & - \\
\hline
\end{tabular}

Values shown for each trait: range, number of fish measured (in brackets), mean value \pm standard error of the mean; ${ }^{\mathrm{M}}$ value of the index calculated based on the data from Muhomediârov (1963); $\mathrm{G}=$ Goreloye (=Bolshoye Ostreche), this study; BOD = Bolshoye Ostreche (=Goreloye), data from Dvorânkin (2005); SP = Sredniy Pert, this study; SPD = Sredniy Pert, data from Dvorânkin (2005); NP = Nizhniy Pert, this study; BK = Bolshoye Krasnoye, this study; BKM = Bolshoye Krasnoye, data from Muhomediârov (1963); BG = Bolshoye Gremyachye, this study; $n=$ sample size; FL = fork length; $W=$ total weight; $\mathrm{NV}=$ number of vertebrae; NSLL $=$ number of scales in lateral line; NGR = number of gill rakers; NDBR = number of branched rays in dorsal fin; NABR = number of branched rays in anal fin; NVBR = number of branched rays in ventral fin; $\mathrm{NPBR}=$ number of branched rays in pectoral fin; VA = ventroanal distance; $\mathrm{AD}=$ antedorsal distance; $\mathrm{AV}=$ anteventral distance; $\mathrm{PV}=$ pectroventral distance; Hmax = maximum body depth; LCP = caudal peduncle length; HL = head length; $\mathrm{NED}=$ horizontal eye diameter; LUJ = upper jaw length; \%HL = as $\%$ of head length. 
differed from fish obtained from other lakes of Bolshoy however, that the size sample from Bolshoye Gremyachye Solovetsky Island. Thus, according to this feature the cis- Lake was quite small.

coes from Bolshoye Gremyachye Lake can be described as The smallest-sized fish were caught from Bolshoye being 'typical' for a Siberian form. It should be noted, Krasnoye Lake (Tables 2, 3). The cisco from Goreloye

Table 3a

Pairwise comparisons of the mean values of morphological traits between ciscoes populations from different lakes of Bolshoy Solovetsky Island

\begin{tabular}{|c|c|c|c|c|c|c|c|c|c|}
\hline \multirow[b]{2}{*}{$\begin{array}{l}\text { Population } \\
\text { code }\end{array}$} & \multicolumn{9}{|c|}{ Trait } \\
\hline & 它 & $\triangleq$ & 之 & $\begin{array}{l}\exists \\
\text { 乙 } \\
\text { Z }\end{array}$ & $\begin{array}{l}\text { 号 } \\
Z\end{array}$ & $\begin{array}{l}\text { 告 } \\
\text { 党 }\end{array}$ & 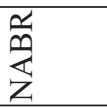 & 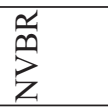 & $\begin{array}{l}\text { 品 } \\
\text { Zे }\end{array}$ \\
\hline G vs. BOD & - & - & $1.66^{\mathrm{ns}}$ & - & $4.92^{* * *}$ & - & $0.00^{\mathrm{ns}}$ & - & - \\
\hline G vs. SP & $48.08^{* * *}$ & $5.75^{* * *}$ & $1.90^{\mathrm{ns}}$ & - & $2.91^{* *}$ & $0.71^{\mathrm{ns}}$ & $1.34^{\mathrm{ns}}$ & $0.71^{\mathrm{ns}}$ & $3.54^{* * *}$ \\
\hline G vs. SPD & - & - & $0.83^{\mathrm{ns}}$ & - & $4.30^{* * *}$ & - & $1.34^{\mathrm{ns}}$ & - & - \\
\hline G vs. NP & $22.98^{* * *}$ & $2.42^{*}$ & $0.95^{\mathrm{ns}}$ & - & $0.60^{\mathrm{ns}}$ & $0.71^{\mathrm{ns}}$ & $0.45^{\mathrm{ns}}$ & $1.79^{\mathrm{ns}}$ & $1.26^{\mathrm{ns}}$ \\
\hline G vs. BK & $97.94^{* * *}$ & $13.83^{* * *}$ & $0.63^{\mathrm{ns}}$ & - & $1.94^{\mathrm{ns}}$ & $2.83^{* *}$ & $1.34^{\mathrm{ns}}$ & - & - \\
\hline G vs. BKM & $90.78^{* * *}$ & - & - & - & $0.95^{\mathrm{ns}}$ & $5.66^{* * *}$ & $4.47^{* * *}$ & - & - \\
\hline G vs. BG & $28.78^{* * *}$ & $11.15^{* * *}$ & $1.60^{\mathrm{ns}}$ & - & - & - & - & - & - \\
\hline BOD vs. SP & - & - & $0.00^{\text {ns }}$ & - & $2.40^{*}$ & - & $1.34^{\mathrm{ns}}$ & - & - \\
\hline BOD vs. SPD & - & - & $1.06^{\mathrm{ns}}$ & - & $0.40^{\mathrm{ns}}$ & - & $1.34^{\mathrm{ns}}$ & - & - \\
\hline BOD vs. NP & - & - & $1.34^{\mathrm{ns}}$ & - & $6.84^{* * *}$ & - & $0.45^{\text {ns }}$ & - & - \\
\hline BOD vs. BK & - & - & $1.79^{\mathrm{ns}}$ & - & $4.71^{* * *}$ & - & $1.34^{\mathrm{ns}}$ & - & - \\
\hline BOD vs. BKM & - & - & - & - & $7.49^{* * *}$ & - & $4.47^{* * *}$ & - & - \\
\hline BOD vs. BG & - & - & $3.13^{* *}$ & - & - & - & - & - & - \\
\hline SP vs. SPD & - & - & $1.34^{\mathrm{ns}}$ & $1.36^{\mathrm{ns}}$ & $1.77^{\mathrm{ns}}$ & - & $0.00^{\text {ns }}$ & - & - \\
\hline SP vs. NP & $73.19^{* * *}$ & $6.60^{* * *}$ & $2.12^{*}$ & $1.41^{\mathrm{ns}}$ & $3.40^{* * *}$ & $0.00^{\mathrm{ns}}$ & $2.83^{* *}$ & $1.34^{\mathrm{ns}}$ & $2.85^{* *}$ \\
\hline SP vs. BK & $158.76^{* * *}$ & $16.83^{* * *}$ & $2.83^{* *}$ & $1.02^{\mathrm{ns}}$ & $1.60^{\mathrm{ns}}$ & $2.12^{*}$ & $0.00^{\mathrm{ns}}$ & - & - \\
\hline SP vs. BKM & $151.61^{* * *}$ & - & - & $3.49^{* * *}$ & $3.35^{* *}$ & $4.95^{* * *}$ & $4.95^{* * *}$ & - & - \\
\hline SP vs. BG & $54.04^{* * *}$ & $14.48^{* * *}$ & $3.40^{* * *}$ & - & - & - & & - & - \\
\hline SPD vs. NP & - & - & $0.00^{\mathrm{ns}}$ & $2.34^{*}$ & $5.40^{* * *}$ & - & $2,83^{* *}$ & - & - \\
\hline SPD vs. BK & - & - & $0.45^{\mathrm{ns}}$ & $2.03^{*}$ & $3.60^{* * *}$ & - & $0.00^{\mathrm{ns}}$ & - & - \\
\hline SPD vs. BKM & - & - & - & $1.40^{\mathrm{ns}}$ & $5.59^{* * *}$ & - & $4.95^{* * *}$ & - & - \\
\hline SPD vs. BG & - & - & $2.46^{*}$ & - & - & - & - & - & - \\
\hline NP vs. BK & $68.87^{* * *}$ & $6.15^{* * *}$ & $0.71^{\mathrm{ns}}$ & $0.14^{\mathrm{ns}}$ & $2.12^{*}$ & $2.12^{*}$ & $2.83^{* *}$ & - & - \\
\hline NP vs. BKM & $61.72^{* * *}$ & - & - & $4.84^{* * *}$ & $0.55^{\mathrm{ns}}$ & $4.95^{* * *}$ & $7.78^{* * *}$ & - & - \\
\hline NP vs. BG & $16.71^{* * *}$ & $6.74^{* * * *}$ & $2.67^{* *}$ & - & - & - & - & - & - \\
\hline BK vs. BKM & $11.31^{* * *}$ & - & - & $4.12^{* * *}$ & $1.94^{\mathrm{ns}}$ & $2.83^{* *}$ & $4.95^{* * *}$ & - & - \\
\hline BK vs. BG & $12.55^{* * *}$ & $2.60^{*}$ & $2.43^{*}$ & - & - & - & - & - & - \\
\hline BKM vs. BG & $9.41^{* * *}$ & - & - & - & - & - & - & - & - \\
\hline
\end{tabular}

Bold denotes comparisons of the number of contemporary ciscoes samples from same lake; FL = fork length; $W=$ total weight; NV = number of vertebrae; NSLL = number of scales in lateral line; NGR $=$ number of gill rakers; NDBR $=$ number of branched rays in dorsal fin; NABR = number of branched rays in anal fin; NVBR = number of branched rays in ventral fin; NPBR = number of branched rays in pectoral fin; VA = ventroanal distance; $\mathrm{AD}=$ antedorsal distance; $\mathrm{AV}=$ anteventral distance; $\mathrm{PV}=$ pectroventral distance; $\mathrm{Hmax}=$ maximum body depth; $\mathrm{LCP}=$ caudal peduncle length; $\mathrm{HL}=$ head length; NED = horizontal eye diameter; LUJ = upper jaw length; VA $\% \mathrm{AD}=\mathrm{VA}$ as $\%$ of $\mathrm{AD} ; \mathrm{G}=$ Goreloye (=Bolshoye Ostreche), this study; BOD = Bolshoye Ostreche (=Goreloye), data from Dvorânkin (2005); SP = Sredniy Pert, this study; $\mathrm{SPD}=$ Sredniy Pert, data from Dvorânkin (2005); NP = Nizhniy Pert, this study; BK = Bolshoye Krasnoye, this study; BKM = Bolshoye Krasnoye, data from Muhomediârov (1963); BG = Bolshoye Gremyachye, this study; The level of significance: ${ }^{\text {ns }} P>0.05 ;{ }^{*} P<0.05 ;{ }^{* *} P<0.01 ;{ }^{* * *} P<0.001$; Time interval between collections varied from 5 years for comparisons G vs. BOD and SP vs. SPD to 55 years for comparison BK vs. BKM. 
Table 3b

Pairwise comparisons of the mean values of morphological traits between ciscoes populations from different lakes of Bolshoy Solovetsky Island (continuation)

\begin{tabular}{|c|c|c|c|c|c|c|}
\hline \multirow{3}{*}{ Population code } & \multicolumn{6}{|c|}{ Trait } \\
\hline & \multirow{2}{*}{ VA $\% A D$} & \multicolumn{5}{|c|}{ As $\%$ of LF } \\
\hline & & $\mathrm{AD}$ & VA & AV & PV & Hmax \\
\hline G vs. BOD & $0.23^{\mathrm{ns}}$ & $2.68^{* *}$ & $1.12^{\mathrm{ns}}$ & $1.39^{\mathrm{ns}}$ & - & $0.55^{\mathrm{ns}}$ \\
\hline G vs. SP & $1,63^{\mathrm{ns}}$ & $7.42^{* * *}$ & $1.66^{\mathrm{ns}}$ & $1.41^{\mathrm{ns}}$ & $2.83^{* *}$ & $2.22^{*}$ \\
\hline G vs. SPD & $0.28^{\mathrm{ns}}$ & $3.54^{* * *}$ & $1.64^{\mathrm{ns}}$ & $0.47^{\mathrm{ns}}$ & - & $0.00^{\mathrm{ns}}$ \\
\hline G vs. NP & $2.89^{* *}$ & $7.16^{* * *}$ & $4.74^{* * *}$ & $1.39^{\mathrm{ns}}$ & $4.24^{* * *}$ & $5.69^{* * *}$ \\
\hline G vs. BK & $0.22^{\mathrm{ns}}$ & $6.34^{* * *}$ & $2.50^{*}$ & $1.11^{\mathrm{ns}}$ & $6.72^{* * *}$ & $8.72^{* * *}$ \\
\hline G vs. BKM & - & $3.80^{* * *}$ & $0.24^{\mathrm{ns}}$ & - & $0.00^{\mathrm{ns}}$ & - \\
\hline G vs. BG & $1.50^{\mathrm{ns}}$ & $7.16^{* * *}$ & $2.89^{* *}$ & - & - & - \\
\hline BOD vs. SP & $2.18^{*}$ & $6.71^{* * *}$ & $0.71^{\mathrm{ns}}$ & $0.55^{\mathrm{ns}}$ & - & $3.54^{* * *}$ \\
\hline BOD vs. SPD & $0.11^{\mathrm{ns}}$ & $1.79^{\mathrm{ns}}$ & 0.83 & $2.77^{* *}$ & - & $0.71^{\mathrm{ns}}$ \\
\hline BOD vs. NP & $3.43^{\mathrm{ns}}$ & $7.07^{* * *}$ & $4.92^{* * *}$ & $1.06^{\mathrm{ns}}$ & - & $8.94^{* * *}$ \\
\hline BOD vs. BK & $0.51^{\mathrm{ns}}$ & $5.37^{* * *}$ & $1.77^{\mathrm{ns}}$ & $4.24^{* * *}$ & - & $10.82^{* * *}$ \\
\hline BOD vs. BKM & - & $2.68^{* * *}$ & $1.39^{\mathrm{ns}}$ & - & - & - \\
\hline BOD vs. BG & $1.44^{\mathrm{ns}}$ & $6.31^{* * *}$ & $2.42^{*}$ & - & - & - \\
\hline SP vs. SPD & $1.80^{\mathrm{ns}}$ & $3.89^{* * *}$ & $0.28^{\mathrm{ns}}$ & $1.89^{\mathrm{ns}}$ & - & $2.83^{* *}$ \\
\hline SP vs. NP & $5.52^{* * *}$ & $2.24^{*}$ & $4.02^{* * *}$ & $0.28^{\mathrm{ns}}$ & $1.41^{\mathrm{ns}}$ & $4.47^{* * *}$ \\
\hline SP vs. BK & $1.53^{\mathrm{ns}}$ & $1.06^{\mathrm{ns}}$ & $1.06^{\mathrm{ns}}$ & $2.77^{* *}$ & $3.89^{* * *}$ & $8.04^{* * *}$ \\
\hline SP vs. BKM & - & $0.89^{\text {ns }}$ & $1.94^{\mathrm{ns}}$ & - & $2.83^{* *}$ & - \\
\hline SP vs. BG & $2.15^{*}$ & $2.46^{*}$ & $2.20^{*}$ & - & - & - \\
\hline SPD vs. NP & $2.22^{\mathrm{ns}}$ & $2.68^{* *}$ & $2.53^{*}$ & $1.94^{\mathrm{ns}}$ & - & $8.05^{* * *}$ \\
\hline SPD vs. BK & $0.50^{\text {ns }}$ & $2.82^{* *}$ & $0.55^{\mathrm{ns}}$ & $0.55^{\text {ns }}$ & - & $10.26^{* * *}$ \\
\hline SPD vs. BKM & - & $1.57^{\mathrm{ns}}$ & $1.89^{\text {ns }}$ & - & - & - \\
\hline SPD vs. BG & $1.36^{\mathrm{ns}}$ & $4.92^{* * *}$ & $1.97^{\mathrm{ns}}$ & - & - & - \\
\hline NP vs. BK & $3.58^{* * *}$ & 0,89 & $2.68^{* *}$ & $3.18^{* *}$ & $2.47^{*}$ & $6.01^{* * *}$ \\
\hline NP vs. BKM & - & 0.24 & $5.06^{* * *}$ & - & $4.24^{* * *}$ & - \\
\hline NP vs. BG & $0.60^{\mathrm{ns}}$ & $3.89^{* * *}$ & $0.99^{\mathrm{ns}}$ & - & - & - \\
\hline BK vs. BKM & - & $0.22^{\mathrm{ns}}$ & $2.77^{* *}$ & - & $6.72^{* * *}$ & - \\
\hline BK vs. BG & $1.60^{\mathrm{ns}}$ & $3.13^{* *}$ & $1.79^{\mathrm{ns}}$ & - & - & - \\
\hline BKM vs. BG & - & $2.65^{* *}$ & $3.02^{* *}$ & - & - & - \\
\hline
\end{tabular}

Table footnotes are below Table $3 \mathrm{a}$.

Lake (which is not part of the canal system which connects the other sampled lakes) did not exhibit substantial morphological differences from other populations.

Polymorphism of creatine kinase isoloci ( $C K-A 1,2 *)$. Polymorphism within the creatine kinase isoloci was studied using 135 fish obtained from four lakes located in the Bolshoy Solovetsky Island (Table 1) and 15 fish from a Finnish lake (Lake Puruvesi), which served as a control. All fish possessed the allele *100 typical of the vendace. The allele variant $* 116$ characteristic for Siberian ciscoes was not found in any of the sampled populations (Fig. 3).

Polymorphism of mitochondrial ND-1 fragment. Ciscoes obtained from the lakes of Bolshoy Solovetsky Island exhibited a low level of mtDNA polymorphism. All populations were dominated by the composite haplotype $\mathrm{E}$ which corresponds to the haplotype PE2 in Politov et al. (2000). This composite haplotype is common in vendace, and has also been recorded in specimens of least cisco and peled, Coregonus peled (Gmelin, 1788) (see Borovikova unpublished*, Borovikova and Artamonova unpublished data). The samples from Lake Bolshoye Krasnoye were the only ones which contained fish with two unique haplotypes (SOL1 and SOL2). Another haplotype ALB1, commonly associated with vendace populations in Northern Russia was also found in some specimens of this lake. Interestingly, one specimen from Bolshoye Krasnoye Lake exhibited heteroplasmy in mtDNA after treatment of the ND-1 fragment by AseI endonuclease (Fig. 4).

The difference between the common haplotype $\mathrm{E}$ and the three other haplotypes recorded during this study is one 
nucleotide substitute at one restriction site of three different restriction enzymes. These are located at the site of $R s a \mathrm{I}$ for SOL1, at the site of HaeIII for SOL2 and at the restriction site of AseI for ALB1. None of the composite haplotypes differ by more than two restriction sites substitutes.

\section{DISCUSSION}

Taxonomic position of ciscoes from Solovetsky Islands. The analysis demonstrated that plastic and meristic characters normally used to discriminate between European and Siberian ciscoes do not allow unambiguous identification of Solovetsky Island ciscoes. The morphological and molecular analyses appear contradictory.

Table 3 c

Pairwise comparisons of the mean values of morphological traits between ciscoes populations from different lakes of Bolshoy Solovetsky Island (continuation)

\begin{tabular}{|c|c|c|c|c|}
\hline \multirow{3}{*}{ Population code } & \multicolumn{4}{|c|}{ Trait } \\
\hline & \multicolumn{2}{|c|}{ As $\%$ of FL } & \multicolumn{2}{|c|}{ As $\%$ of $\mathrm{HL}$} \\
\hline & LCP & HL & NED & LUJ \\
\hline G vs. BOD & - & $7.07^{* * *}$ & - & - \\
\hline G vs. SP & $0.63^{\mathrm{ns}}$ & $0.45^{\mathrm{ns}}$ & $2.23^{*}$ & $4.07^{* * *}$ \\
\hline G vs. SPD & - & $7.60^{* * *}$ & - & - \\
\hline G vs. NP & $0.63^{\mathrm{ns}}$ & $0.00^{\mathrm{ns}}$ & $1.49^{\mathrm{ns}}$ & $3.85^{* * *}$ \\
\hline G vs. BK & $2.22^{*}$ & $8.13^{* * *}$ & $4.46^{* * *}$ & $1.49^{\mathrm{ns}}$ \\
\hline G vs. BKM & $1.94^{\mathrm{ns}}$ & $11.18^{* * *}$ & $2.97^{* *}$ & - \\
\hline G vs. BG & - & - & - & - \\
\hline BOD vs. SP & - & $9.39^{* * *}$ & - & - \\
\hline BOD vs. SPD & - & $1.34^{\mathrm{ns}}$ & - & 一 \\
\hline BOD vs. NP & - & $8.94^{* * *}$ & 一 & 一 \\
\hline BOD vs. BK & - & $1.06^{\mathrm{ns}}$ & - & 一 \\
\hline BOD vs. BKM & - & $2.24^{*}$ & 一 & 一 \\
\hline BOD vs. BG & - & - & - & - \\
\hline SP vs. SPD & - & $12.73^{* * *}$ & - & - \\
\hline SP vs. NP & $0.00^{\mathrm{ns}}$ & $0.71^{\mathrm{ns}}$ & $1.39^{\mathrm{ns}}$ & $0.83^{\text {ns }}$ \\
\hline SP vs. BK & $2.68^{* *}$ & $10.73^{* * *}$ & $3.06^{* *}$ & $3.80^{* * *}$ \\
\hline SP vs. BKM & $4.02^{* * *}$ & $18.38^{* * *}$ & 1.20 & - \\
\hline SP vs. BG & - & - & - & - \\
\hline SPD vs. NP & $12.02^{* * *}$ & - & - & - \\
\hline SPD vs. BK & - & $2.68^{* *}$ & - & - \\
\hline SPD vs. BKM & - & $5.66^{* * *}$ & - & - \\
\hline SPD vs. BG & - & - & - & - \\
\hline NP vs. BK & $2.68^{* *}$ & $10.29^{* * *}$ & $4.99^{* * *}$ & $3.58^{* * *}$ \\
\hline NP vs. BKM & $4.02^{* * *}$ & $17.68^{* * *}$ & $2.46^{*}$ & - \\
\hline NP vs. BG & - & - & - & - \\
\hline BK vs. BKM & $5.30^{* * *}$ & $0.89^{\mathrm{ns}}$ & $1.40^{\mathrm{ns}}$ & - \\
\hline BK vs. BG & - & - & - & - \\
\hline BKM vs. BG & - & - & - & - \\
\hline
\end{tabular}

Table footnotes are below Table 3a.
On one hand, morphological characters indicate that fish from Solovetsky Archipelago represent an intermediate form between the vendace and least cisco. Yet molecular characteristics are typical of a European form; neither mitochondrial nor nuclear markers show any 'Siberian' alleles in the sampled populations.

However, morphological attributes could be influenced by environmental factors. It is known, for example, that temperature is one of the most important factors affecting coregonid development; at low temperatures development is slower resulting in the greater number of body segments (Eckmann 1987). The development of ciscoes from Solovetsky Islands and from Siberia takes place at lower temperatures in comparison with most vendace populations.

This may explain the greater number of vertebrae compared to vendace that live at lower latitudes. Borovikova (unpublished*) demonstrated that the proportion of fish with greater vertebrae number increases from South to North (Fig. 5). At the same time, the number of vertebrae in ciscoes from lakes Vodlozero (Baltic basin) and Beloye (upper Volga basin) is typical of the vendace although these populations carry traces of 'least cisco' allele introgression (Borovikova and Makhrov 2009, Borovikova unpublished*).

Some other differences among vendace populations may be also related with phenotypic plasticity that is typical for Coregonus (see Etheridge et al. 2012 and references therein). Morphological characteristics are more likely to reflect ecological factors and not the origin of Solovetsky populations of ciscoes. Although we cannot draw definite conclusions based on biological and genetic data about the origin of ciscoes of Solovetsky Archipelago - whether it was a natural range expansion or human introduction - low genetic diversity of local populations and lack of differentiation among composite haplotypes of mtDNA indicates that the latter is more likely.

This is further supported by the fact that the detailed description of the Solovetsky monastery and islands at the start of 19th century by Solovetsky abbot Dosifej (1836) does not mention ciscoes. Neither does the diary of Čeliŝev (1886) who visited the islands in late 18th century. Both authors provided detailed lists of the fish inhabiting Solovetsky lakes. At the same time, as evidenced by one of the lay brothers of Solovetsky monastery, several new species of fish including vendace have been introduced in the lakes of Bolshoy Solovetsky Island in the second half of 19th century (Grimm 1886).

Data contained in the available literature allowed comparisons of morphology of fish collected from a number of lakes at different times (Tables 2, 3). From the data available, no major changes in morphology of the cisco population from Lake Goreloye (=Bolshoye Ostrechye) appear to be evident within the last five years. At the same time many of the morphological traits of the cisco from Lake Bolshoye Krasnoye were significantly changed during more substantial period of time ( 50 years). At first it was mentioned by Kuzisiin et al. (1999) for number of the vertebrae.

The distribution of least cisco in Europe and its taxonomic position. All of the above shows that morphologi- 


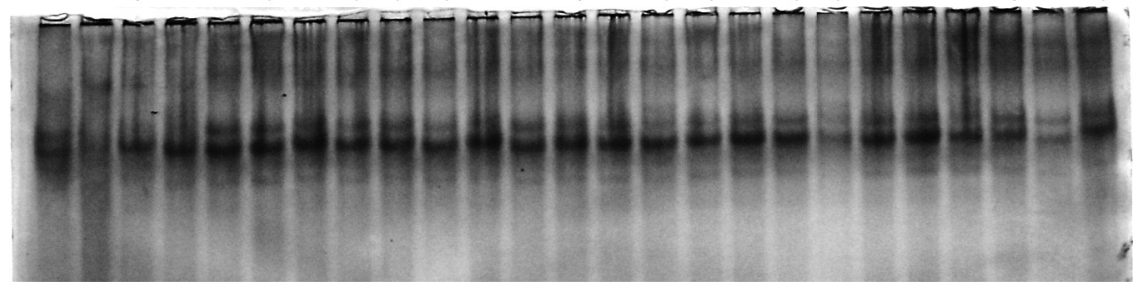

Fig. 3. Creatine kinase electrophoregram demonstrating allelic composition in the cisco population from Lake Goreloye (lanes 3-22) as compared to trout, Salmo trutta (lane 1), Atlantic salmon, S. salar (lane 2), and vendace, Coregonus albula, from Lake Puruvesi, Finland (lanes 23-25)

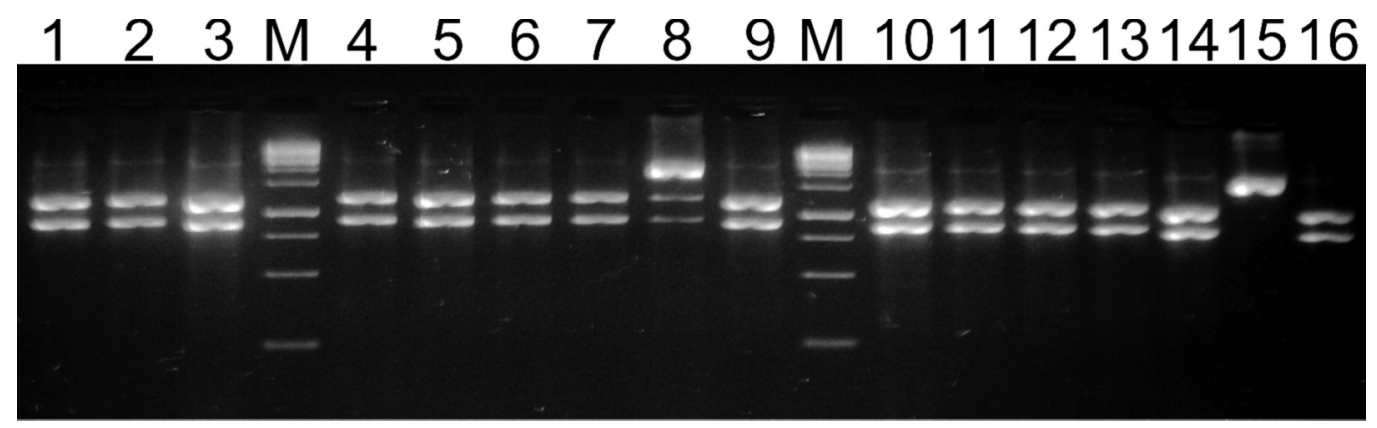

Fig. 4. Polymorphism at the AseI restriction site in the cisco population from Lake Bolshoye Krasnoye; haplotypes by lanes: AseI restriction site present (1-7, 9-14, 16); AseI restriction site absent (15); specimen exhibited heteroplasmy in mtDNA (8); $\mathrm{M}=$ GeneRuler ${ }^{\mathrm{TM}} 1 \mathrm{~kb}$ DNALadder ('Fermentas', Lithuania)

cal characters are not very reliable in distinguishing European and Siberian ciscoes, because to a large degree they are affected by environmental conditions. Thus, it appears that molecular-genetic methods are better suited for resolving the problems of taxonomic status, phylogenetic relations and distribution of the two forms (species).

According to our molecular data Bolshoy Solovetsky Island is inhabited by 'typical' vendace, Coregonus albula. This species is also found on the west and east coast of the White Sea (Sendek et al. 2012, Borovikova unpublished*). Further south, where the basins of Volga River, Baltic and White Seas connect, some populations carry genetic characteristics of both European and Siberian forms. For example, samples from Lake Vodlozero (the easternmost part of Baltic catchment) carried a haplotype of mtDNA characteristic of a Siberian species (Borovikova and Makhrov 2009). The populations of Lake Beloye (upper reaches of Volga), Lake Vodlozero and several other water bodies of Eastern Baltic basin, two lakes in the basin of Onega river (southern part of White Sea drainage basin) contained alleles of creatine kinase isoloci typical for least cisco (Gordeeva et al. 2009, Borovikova unpublished*). It should be noted that according Gordeeva et al. (2009) frequency one of these alleles in Lake Goreloye (Bolshoy Solovetsky Island) is 0.5 . However, electrophoregram, on which this claim is based, is not included in the cited paper, which let us doubt the data these authors. The basin of the Pechora River had both populations with high frequency of an allele typical of C. albula and populations with great affinity to $C$. sardinella (see Sendek 2002).

All of the above is most likely related to the dispersal of ciscoes across northern Europe before and after the last glacial period. Before the last glacial period ciscoes were gradually colonizing European waters in a westward direction from Siberia. This formed a large 'transitional' area where 'typical Siberian' alleles were gradually substituted by 'typical European' ones. Later, the glacier cover of the Eurasian North divided the distribution range of this single species into three parts: European, Siberian (Fig. 1, refugium I), and a refugium near the present-day location of the Volga, Baltic and White Sea basins (Fig. 1, refugium II).

The populations located in this refugium are the descendants of the fish from the 'transitional' area that existed before glaciation (Fig. 1, refugium II). These fish may not seem to have contributed to the colonization of the newly available territories after ice retreat. These territories were colonized mainly by the ciscoes from the west (vendace) and by fish present in the basin of the presentday Onega Lake (Fig. 1, refugium III). It is likely, that near Pechora River, where the ciscoes dispersing from the west met the remnants of Siberian populations (least cisco), hybridization of the two forms took place. However, the two forms did not merge completely mainly, it appears, due to their differing ecology and, in particular, their vastly different habitat preferences (vendace inhabits lakes whereas least cisco is a semi-anadromous fish).

The differences in ecology might have led to changes in the morphological traits, so the changes in the body proportions being apparently adaptive (Borovikova and Mahrov 2012). We mentioned earlier the relation between the temperature during embryogenesis and the number of the vertebrae (Eckmann 1987, Lindsey 1988, Etheridge et al. 2012). Many of the head features could be changed by 


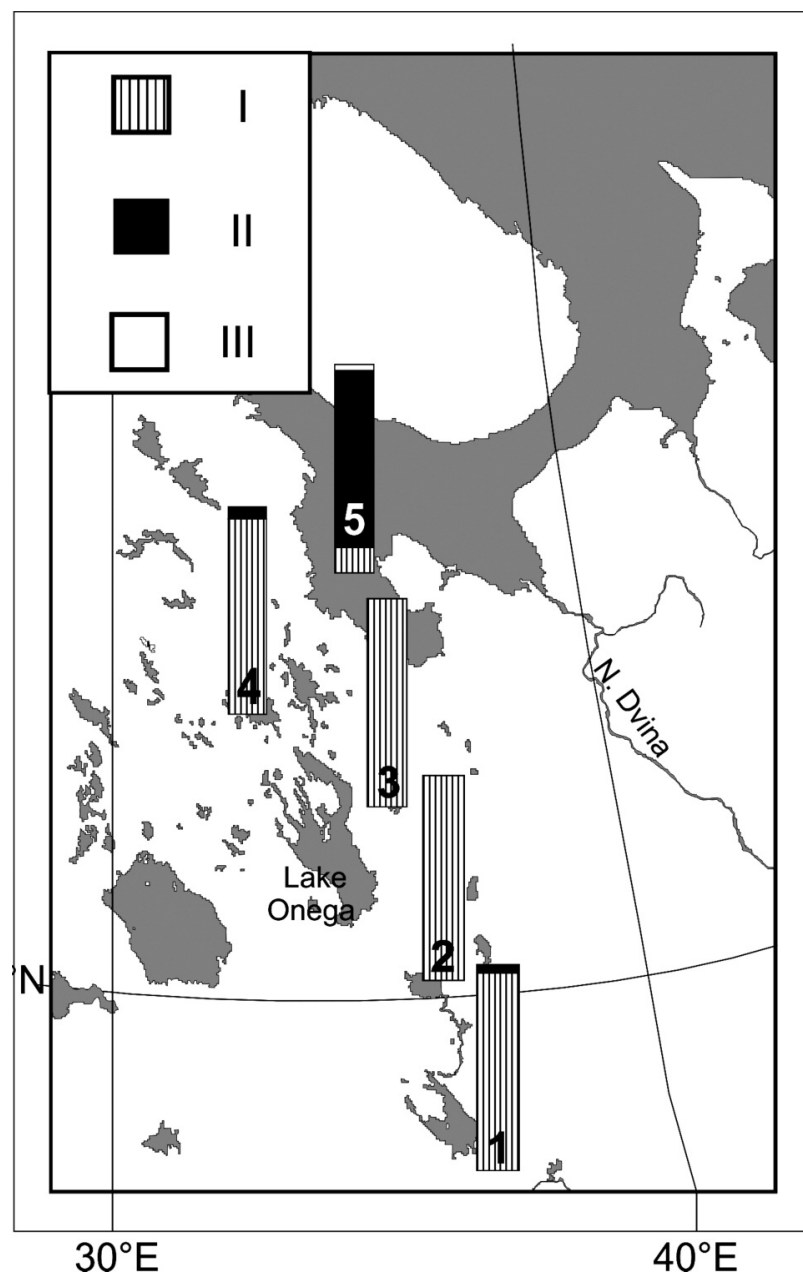

Fig. 5. Proportions of specimens in ciscoes populations with different numbers of vertebrae $\left(\chi^{2}=1731.62 ; d f\right.$ = 8; $P<0.001) ; 1=$ Lake Plescheevo; $2=$ Lake Beloye; 3 = Lake Vodlozero; 4 = Lake Segozero; $5=$ Lakes of Bolshoy Solovetsky Island: Sredniy Pert, Nizhniy Pert, Boshoye Krasnoye, Gremyachye, and Goreloye; Roman numerals indicate: I = proportion of fish with the number of vertebrae ranging between 54 and 56 (more typical for vendace); II = proportion of fish with the number of vertebrae ranging between 57 and 59 (this interval are generated by the overlap of the diagnostic intervals for $C$. albula and $C$. sardinella: 54-59 and 57-64, respectively); III = proportion of fish with the number of vertebrae ranging between 60 and 64 (more typical for least cisco)

the diet composition of fish (Men'šikov 1951, Meyer 1987, Balon 1989, Wimberger 1991). Body shape and position of the fins likely indicate ability to long-term migration (Belâeva 1951, Burmakin 1953).

Therefore many of the morphological features are likely to reflect the transition of the cisco from the semianadromous life history type to the lacustrine type, which is more characteristic of the European form. Thus, the speciation of the vendace is clearly adaptive, at least with respect to some traits. It should be noted, however, that the results of this study raise doubts as to whether the vendace has entirely diverged from the least cisco, and whether the speciation has been completed. At the same time, all available morphological and molecular genetic data show only slight differences between the vendace (Coregonus albula) and the least cisco (C. sardinella) (see Pokrovskij 1967, Bernatchez et al. 1991, Bodaly et al. 1991, Kuziŝin et al. 1999, Romanov 2000, Sendek 2002, Borovikova and Makhrov 2009), along with wide transitional zone between these forms, makes it possible to hypothesise that Eurasian ciscoes are actually a single species (C. albula). Thus our results support previous data about the existence, in northern Europe, populations characterized by transitional features between 'typical' vendace and 'typical' least cisco. This fact allows revising the current state of the systematic of the ciscoes.

\section{ACKNOWLEDGEMENTS}

The authors thank Dr. A.M. Naseka and I.A. Petrushenkova for assistance with the study and Dr. Margaret Platell (University of Newcastle) for her comments and suggestions on the manuscript. This work was funded by grants from the President of Russian Federation for support of young scientists, projects MK-2049.2013.4, MK-2455.2013.4; the Russian Academy of Sciences (RAS) Presidium Program "Life Nature: Present state and problems of development" (Sub-Program "Dynamics and conservation of Gene Pools") and RFBR grants No. 11-04-00697-a and 13-04-90814.

\section{REFERENCES}

Balon E.K. 1989. The epigenetic mechanisms of bifurcation and alternative life-history styles. Pp. 467-501. In: Bruton M.N. (ed.) Alternative life-history styles of animals. Perspectives in vertebrae science 6. Kluwer Academic Publishers, Dordrecht, the Netherlands.

Bănărescu P. 1991. Distribution and dispersal of freshwater animals in North America and Eurasia. Pp. 512-729. In: Zoogeography of fresh waters. Aula-Verlag, Wiesbaden, Germany.

Belâeva K.I. [Belyaeva K.I.] 1951. Râpuška Coregonus albula L. Topozera. [Vendace Coregonus albula L. of the Lake Topozero.] Trudy Karelo-Finskogo otdeleniâ VNIORH, Petrozavodsk 2: 69-88. [In Russian.]

Berg L.S. 1916. Ryby presnyh vod Rossijskoj imperii. [Fishes of fresh waters of the Russian Empire.] Departament zemledeliâ, Moskva [Department of Agriculture, Moscow.] [In Russian.]

Bernatchez L., Colombani F., Dodson J.J. 1991. Phylogenetic relationships among the subfamily Coregoninae as revealed by mitochondrial DNA restriction analysis. Journal of Fish Biology 39 (Suppl. sA): 283-290. DOI: 10.1111/j.10958649.1991.tb05091.x

Bodaly R.A., Vuorinen J., Ward R.D., Luczynski M., Reist J.D. 1991. Genetic comparisons of New and Old World coregonid fishes. Journal of Fish Biology 38 (1): 37-51. DOI: 10.1111/j.1095-8649.1991.tb03089.x

Borovikova E.A., Makhrov A.A. 2009. Detection of the mitochondrial DNA haplotype characteristic of the least cisco (Coregonus sardinella Valenciennes, 1848) in the vendace 
(C. albula Linnaeus, 1758) population of Vodlozero (the Baltic Sea basin). Biology Bulletin 36 (1): 80-83. DOI: 10.1134/S1062359009010129

Borovikova E.A., Mahrov A.A. [Makhrov A.A.] 2012. Izučenie populâcij perehodnoj zony meždu evropejskoj i sibirskoj râpuškami (Coregonus): rol' sredy obitaniâ v vidoobrazovanii. [Study of Coregonus populations in the zone of intergradation between the vendace and least cisco: the role of the environment in speciation.] Principy èkologii 1.4 (4): 5-18. [In Russian with English summary.]

Burmakin E.V. 1953. Biologiâ i rybohozâjstvennoe značenie pelâdi. [Biology and commercial significance of the peled.] Trudy Barabinskogo otdeleniâ VNIORH 6 (1): 25-90. [In Russian.]

Cronin M.A., Spearman W.J., Wilmot R.L., Patton J.C., Bickham J.W. 1993. Mitochondrial DNA variation in Chinook (Oncorhynchus tshawytscha) and chum salmon (O. keta) detected by restriction enzyme analysis of polymerase chain reaction (PCR) products. Canadian Journal of Fisheries and Aquatic Sciences 50 (4): 708-715. DOI: 10.1139/f93-081

Čeliŝev P.I. [Chelischev P.I.] 1886. Putešestvie po Severu Rossii v 1791 godu. [A travel through Russian North in 1791.] Tipografiâ V.S. Balašova, S.-Peterburg [V.S. Balashov Typography, St.-Petersburg.] [In Russian.]

Dosifej [Dosifei] 1836. Geografičeskoe, istoričeskoe i statističeskoe opisanie stavropigial'nogo pervoklassnogo Soloveckogo monastyrâ. Čast' 1. [Geographical, historical, and economical description of the stauropegial first-class Solovetsky monastery. Part 1.] V Universitetskoj tipografii, Moskva. [Typography of the University, Moscow.] [In Russian.]

Drâgin P.A. [Dryagin P.A.] 1933. Belozerskaâ râpuška i vopros akklimatizacii sigovyh v Belom ozere. [The vendace of the Beloye Lake and a problem of coregonids acclimatization in Beloye Lake.] Izvestiâ VNIORH 16: 22-39. [In Russian.]

Dvorânkin G.A. [Dvorjankin G.A.] 2005. Ozera Soloveckogo arhipelaga: osobennosti ihtiofauny i sostoânie promysla. [Lakes of the Solovetsky Archipelago: peculiarities of fish fauna and state of fishery.] Pp. 239-246. In: Materialy otčetnoj sessii SevPINRO po itogam NIR 2002-2003 godov [Proceedings of Northern Branch of Polar Research Institute of Marine Fisheries and Oceanography accounting session.] Arhangel'sk/Arkhangelsk. [In Russian.]

Eckmann R. 1987. A comparative study on the temperature dependence of embryogenesis in three coregonids (Coregonus spp.) from Lake Constance. Schweizerische Zeitschrift für Hydrologie 49 (3): 353-362.

Etheridge E.C., Adams C.E., Bean C.W., Durie N.C., Gowans A.R.D., Harrod C., Lyle A.A., Maitland P.S., Winfield I.J. 2012. Are phenotypic traits useful for differentiating among a priori Coregonus taxa? Journal of Fish Biology 80 (2): 387-407. DOI: 10.1111/j.1095-8649. 2011.03189.x

Gaál Ö., Medgyesi G.A., Vereczkey L. 1980. Electrophoresis in the separation of biological macromolecules. John Wiley and Sons, Chichester, New York, Brisbane, Toronto.

Gordeeva N.V., Kholod O.N., Dvoryankin G.A., Sendek D.S., Sterligova O.P. 2009. On the origin of Solovetskaya ven- dace Coregonus albula and of the Syamozero smelt Osmerus eperlanus. Journal of Ichthyology 49 (1): 23-31. DOI: $10.1134 / \mathrm{S} 0032945209010032$

Grimm O. 1886. O kitobojnom promysle na Murmane. [About whale catching (whaling) on Murman.] Tipografiâ V. Demakova, S.-Peterburg [V. Demakov Typography, St.Petersburg.] [In Russian.]

Green M.R., Sambrook J. 2012. Molecular cloning: a laboratory manual. Gold Spring Harbor Laboratory Press, Gold Spring Harbor, NY, USA.

Hudson A.G., Vonlanthen P., Müller R., Seehausen O. 2007. Review: The geography of speciation and adaptive radiation in coregonines. Advances in Limnology 60: 111-146.

Ivanter È.V., Korosov A.V. 2003. Vvedenie v količestvennuû biologiû. [Introduction in quantitative biology.] Petrozavodsk: PetrGU [Petrozavodsk University publishing house]. [In Russian.]

Kottelat M., Freyhof J. 2007. Handbook of European freshwater fishes. Kottelat, Cornol, Switzerland and Freyhof, Berlin, Germany.

Kuderskij L.A. [Kudersky L.A.] 1987. Puti formirovaniâ severnyh èlementov ihtiofauny Severa evropejskoj territorii SSSR. [Formation ways of the northern elements of the ichthyofauna on European North of the USSR.] Sbornik naučnyh trudov GosNIORH 258: 102-121. [In Russian.]

Kuziŝin K.V. [Kuzishin K.V.], Gruzdeva M.A., Andreeva A.P., Mahrov A.A. [Makhrov A.A.], Golubev A.V., Novikov G.G. 1999. K voprosu o taksonomičeskom statuse râpuški (Coregonidae, Osteichthyes) Soloveckih ostrovov. [A problem of taxonomic status of Solovetsky islands ciscoes (Coregonidae, Osteichthyes).] Pp. 135-136. In: Danilov P.I. (ed.) Biologičeskie osnovy izučeniâ, osvoeniâ i ohrany životnogo i rastitel'nogo mira, počvennogo pokrova Vostočnoj Fennoskandii. Tezisy dokladov meždunarodnoj konferencii i vyezdnoj sessii Otdeleniâ obŝej biologii RAN, 6-10 sentâbrâ 1999, Petrozavodsk, Rossiâ. [Biological grounds of the study, development and conservation of the Eastern Fennoscandia fauna, flora and soil cover. Abstract book of the International conference and exit session of the section of general biology of RAS, 6-10 September 1999, Petrozavodsk, Russia.] [In Russian.]

Lindsey C.C. 1988. Factors controlling meristic variation. Pp. 179-274. In: Hoar W.S., Randall D.J. (eds.). Fish physiology. Vol. 11 B. Academic Press, New York, USA.

Makhrov A.A., Bolotov I.N. 2006. Dispersal routes and species identification of freshwater animals in northern Europe: A review of molecular evidence. Russian Journal of Genetics 42 (10): 1101-1115. DOI: 10.1134/S1022795406100036

Men'šikov M.I. 1951. Nekotorye zakonomernosti vozrastnoj i geografičeskoj izmenčivosti ryb. [Some mechanisms of the morphological variability of the fish depended on its age and geographical distribution.] Trudy Karelo-Finskogo otdeleniâ VNIORH 3: 292-306. [In Russian.]

Meyer A. 1987. Phenotypic plasticity and heterochrony in Cichlasoma managuense (Pisces, Cichlidae) and their implications for speciation in cichlid fishes. Evolution 41 (6): 1357-1369.

Muhomediârov F.B. [Mukhomediyarov F.B.] 1963. Râpuška soloveckaâ (bassejn Belogo morâ). [Ciscoes of the 
Solovetsky Islands (White Sea basin).] Problemy ispol'zovaniâ promyslovyh resursov Belogo morâ i vnutrennih vodoemov Karelii. [The problems in using the commercial resources of the White Sea and Karelian inland water bodies.] 1: 206-210. [In Russian.]

Peacock A.C., Bunting S.L., Queen K.G. 1965. Serum protein electrophoresis in acrylamide gel: Patterns from normal human subjects. Science 147 (3664): 1451-1453. DOI: 10.1126/science.147.3664.1451

Perelygin A.A. 1992. Genetic variability of proteins in the populations of vendace (Coregonus albula) and least cisco (Coregonus sardinella). Nordic Journal of Freshwater Research 67: 99.

Pervozvansky V.Y. 1999. The effect of the Grosswald periglacial discharge system on the distribution pattern of Eurasian Coregonidae. P. 70. In: VII International Symposium on the biology and management of coregonid fishes, 9-12 August 1999, Ann Arbor, Michigan, USA.

Pokrovskij V.V. [Pokrovsky V.V.] 1967. O morfologičeskih osobennostâh, proishoždenii i geografičeskom rasprostranenii belomorskoj râpuški Coregonus sardinella maris-albi Berg. [About morphological features, origin and geographical distribution Coregonus sardinella maris-albi Berg.] Izvestiâ GosNIORH 62: 100-114. [In Russian.]

Politov D.V., Gordon N.Yu., Afanasiev K.I., Altukhov Yu.P., Bickham J.W. 2000. Identification of Palearctic coregonid fish species using mtDNA and allozyme genetic markers. Journal of Fish Biology 57 (Suppl. sA): 51-71. DOI: 10.1006/jfbi.2000.1608

Pravdin I.F. 1966. Rukovodstvo po izučeniû ryb. [Manual on fish study (mainly freshwater species).] Piŝevaâ promyšlennost', Moskva [In Russian.]

Rešetnikov Û.S. [Reshetnikov Yu.S.] (ed.) 2003. Atlas presnovodnyh ryb Rossii. Tom 1. [Atlas of Russian freshwater fishes. Vol. 1.] Nauka, Moskva/Moscow. [In Russian.]

Romanov V.I. 2000. Morfoèkologičeskaâ harakteristika râpuški oz. Tommot (bassejn r. Hatangi) i nekotorye diskussionnye voprosy sistematiki evrazijskih râpušek. [Morphoecological characteristics of Coregonus from the Lake Tommot (River Khatanga basin) and some disputable questions of European Coregonus systematics.] Sibirskij èkologičeskij žurnal 3: 293-303. [In Russian with English summary.]

Segerstråle S.G. 1976. Proglacial lakes and the dispersal of glacial relicts. Commentationes biologicae, Societas Scientiarium Fennica 83: 15.
Sendek D.S. 2002. Electrophoretic studies of coregonid fishes from across Russia. Advances in Limnology 57: 35-55.

Sendek D.S., Novoselov A.P., Studenov I.I., Gurichev P.A. 2012. The origin of coregonid fishes of the White Sea Kuloi Plateau. Advances in Limnology 63: 209-227.

Smitt F. 1886. Kritisk förteckning öfver dei Risk museum befentliga salmonider. Kongliga Svenska vetenskapsakademiens handlingar.

Svärdson G. 1988. Pleistocene age of spring-spawning cisco, Coregonus trybomi. Nordic Journal of Freshwater Research 64: 101-112.

Svendsen J.I., Alexanderson H., Astakhov V.I., Demidov I., Dowdeswell J.A., Funder S., Gataullin V., Henriksen M., Hjort C., Houmark-Nielsen M., Hubberten H.W., Ingólfsson Ó., Jakobsson M., Kjær K.H., Larsen E., Lokrantz H., Lunkka J.P., Lyså A., Mangerud J., Matiouchkov A., Murray A., Möller P., Niessen F., Nikolskaya O., Polyak L., Saarnisto M., Siegert C., Siegert M.J., Spielhagen R.F., Stein R. 2004. Late Quaternary ice sheet history of northern Eurasia. Quaternary Science Reviews 23 (11-13): 1229-1271. DOI: 10.1016/j.quascirev.2003.12.008

Truveller K.A., Nefëdov G.N. 1974. Mnogocelevoj pribor dlâ vertikal'nogo èlektroforeza $\mathrm{v}$ parallel'nyh plastinah poliakrilamidnogo gelâ. [Multipurpose apparatus for vertical electrophoresis in parallel plates of polyacrylamide gel.] Naučnye doklady vysšej školy seriâ Biologičeskie nauki 9: 137-140. [In Russian.]

Vonlanthen P., Bittner D., Hudson A.G., Young K.A., Müller R., Lundsgaard-Hansen B., Roy D., Di Piazza S., Largiader C.R., Seehausen O. 2012. Eutrophication causes speciation reversal in whitefish adaptive radiations. Nature 482: 357-363. DOI: 10.1038/nature 10824

Wimberger P.H. 1991. Plasticity of jaw and skull morphology in the Neotropical cichlids Geophagus brasiliensis and G. steindachneri. Evolution 45: 1545-1563.

Zahvatkin A.A. 1927. Soloveckie ozera. [Lakes of the Solovetsky Islands.] Materialy Soloveckogo obŝestva kraevedeniâ. [Solovetsky society of local history.] Solovki. [In Russian.]

Received: 26 September 2012 Accepted: 7 May 2013 Published electronically: 30 September 2013 